\title{
Characterization and Adsorption Applications of Composite Biochars of Clay Minerals and Biomass
}

Lihui Gao ( $\square$ lihuigaocumt@163.com )

China University of Mining and Technology

Jillian L. Goldfarb

Cornell University

\section{Research Article}

Keywords: Composite biochar, clay minerals, pyrolysis, adsorption, multilinear model

Posted Date: March 16th, 2021

DOI: https://doi.org/10.21203/rs.3.rs-295822/v1

License: (c) (i) This work is licensed under a Creative Commons Attribution 4.0 International License. Read Full License

Version of Record: A version of this preprint was published at Environmental Science and Pollution Research on April 13th, 2021. See the published version at https://doi.org/10.1007/s11356-021-13858-x. 
1 Characterization and adsorption applications of composite biochars of clay

2 minerals and biomass

$3{\text { Lihui } \mathrm{Gao}^{1 *} \text { and Jillian L. Goldfarb }}^{2}$

4 1. School of Environment and Spatial Informatics, China University of Mining and Technology, Xuzhou 221116, People's Republic of China

2. Department of Biological and Environmental Engineering, Cornell University, 226 Riley-Robb Hall, Ithaca, NY 14853, USA

9 Abstract: Composite mineral-biochars of a homogeneous biomass (cellulose) and heterogeneous biomass (oak leaves) were fabricated with either $5 w t \%$ or $10 w t \%$ minerals (montmorillonite (MMT), kaolinite, and sand), and then pyrolyzed at $600{ }^{\circ} \mathrm{C}$ for $60 \mathrm{~min}$. Characterizations including proximate analysis, ultimate analysis, surface area and porosity, morphology and surface chemistry confirmed that minerals were present on the surface of biochar, and MMT/kaolinite-biochar composites showed a strengthening in the chars' aromatic structures, as well as increases in oxygencontaining surface functional groups. Methylene blue adsorption isotherms indicated that the MMT/kaolinite-biochars had higher adsorption capacities than pure biomass or biomass-sand biochars $\left(110 \mathrm{mg}_{\mathrm{MB}} / \mathrm{g}_{\mathrm{char}}\right.$ and $24 \mathrm{mg}_{\mathrm{MB}} / \mathrm{g}_{\text {char }}$ for MMT-cellulose char and cellulose char, respectively). A multilinear model relating adsorption capacity and adsorbent properties was developed to measure the relative contribution of biochar

21 properties to adsorption behavior. The model indicates that pore volume and hydrogen

\footnotetext{
* To whom correspondence should be addressed (lihuigaocumt@163.com)
} 

onto the biochars. Findings from this work indicate that composite biochars prepared from biomass and inexpensive clay minerals are a promising adsorbent for remediating organic contaminants from water.

26

Keywords: Composite biochar; clay minerals; pyrolysis; adsorption; multilinear model 


\section{Introduction}

Biochar, a carbonaceous solid resulting from biomass pyrolysis under inert conditions, has gained much attention because of its promising application as a soil amendment, or, upon upgrading into activated carbons, as fuel cell and supercapacitor electrodes, gas adsorbents, and for water treatment to remove a variety of organic and inorganic contaminants(Dehkhoda et al., 2016a, 2016b; Kimetu et al., 2014; Tan et al., 2017, 2015; Wu et al., 2017). Multiple methods (e.g. chemical and physical activation techniques(Istan et al., 2016; Tay et al., 2009; Vijayalakshmi et al., 2010)) have been developed to modify biochar and increase its adsorption capacity for various pollutants in the aqueous environment.

Due to their unique layered structure, high specific surface area and ion exchange capacity, clay minerals show great potential in agriculture as well as in industrial and petroleum engineering(Murray, 1991). Among them, montmorillonite and kaolinite are perhaps the most studied clays across various research areas. Montmorillonite (MMT) is a 2:1 layered aluminosilicate, and there are exchangeable cations $\left(\mathrm{Na}^{+}, \mathrm{K}^{+}, \mathrm{Ca}^{2+}\right.$, etc.) with strong electron-acquiring ability and adsorption performance between the layers. One important characteristic of MMT is that the layers are negative charged, and the charge is usually balanced by hydrated cations located within the interlayer space(Segad et al., 2010). Kaolinite is a 1:1 layered aluminosilicate; the internal charge is close to balanced, and there are no exchangeable cations or water molecules between the layers(Chen et al., 1999). Thus, the exchange sites of kaolinite are only located on the surface. Yet, both clays have been shown - in raw and modified forms - to be 
effective adsorbent materials for a range of environmental contaminants. For example, Sherbini and Hassanien(Abou-El-Sherbini and Hassanien, 2010) used 2Oxyhydrazino-N-(2-methylen-yl-hydroxyphenyl)pyridinium (OMHP) ion to modify MMT to remove $\mathrm{Cu}(\mathrm{II})$, results showed that OMHP-MMT had a good removal efficiency and selectivity towards $\mathrm{Cu}(\mathrm{II})$ with a removal capacity of $119 \mathrm{mEq} / 100 \mathrm{~g}$. Jiang et al.(Jiang et al., 2010) used kaolinite clay to adsorb heavy metal ions from wastewater; their results showed that the adsorption capacity of kaolinite for $\mathrm{Pb}^{2+}$ reached $160 \mathrm{mg} / \mathrm{L}$ under the synergistic mechanisms of adsorption and ion exchange. However, MMT and kaolinite may not be suitable as fixed-bed media or additives in water treatment due to their fine particle size (i.e., colloids/nanoparticles).

Engineering methods have been widely applied to create biochar-based materials with upgraded functionalities for environmental applications. In such biochar-based composites, biochar provides a porous structure that can support clay micro- and nanoparticles within the carbonaceous matrix. Therefore, a simple method was developed to synthesize mineral-biochar material for environmental applications. In order to investigate the upgraded performance of clay minerals on different biomass substrates, two different biomasses ("homogeneous" biomass, microcrystalline cellulose; a "heterogeneous" biomass, dried oak leaves) were selected and each was mixed well with one of the clay minerals prior to pyrolysis. The physicochemical properties of these pyrolyzed chars were characterized. In addition, the adsorption property of engineering bio-chars to methylene blue (MB), which is regarded as a “model” organic compound for adsorption(Gao and Goldfarb, 2019; Yao et al., 2014), 
was measured to evaluate the potential application in environmental remediation. Therefore, the objectives of this research are to: (1) prepare mineral-biochar composites; (2) characterize their physiochemical properties; (3) measure the adsorption ability to remove MB; (4) explore the adsorption mechanisms of MB adsorb onto the composites.

\section{Material and Methods}

\subsection{Biochar fabrication}

Cellulose (Alfa Aesar) was supplied by Fisher Scientific. Oak leaves were collected in Boston, MA in late October / early November 2016 from a representative set of trees. To remove dust, leaves were washed in deionized water and dried in a laboratory oven to prevent degradation. The leaves were ground and sieved to a particle size fraction of 100 to $300 \mu \mathrm{m}$. Raw biomasses were blended with sand (Sigma-Aldrich), kaolinite (Fisher scientific,), or montmorillonite clay (Sigma-Aldrich), at $5 w t \%$ and 10 $w t \%$ mineral loadings. Samples were weighed directly into a glass vial to the $0.1 \mathrm{mg}$, and homogenized on a vortex mixer. The characteristics of the biomass feedstock and three types of minerals were showed in Table S1-2 and Figure S1-3 in supplemental information.

Biochar was fabricated by pyrolyzing between 1.5 and $2 \mathrm{~g}$ of raw biomass or biomass-mineral blend in a 2" MTI tube furnace. A large number of studies have shown that the biochar-based composites synthesized via pyrolysis at $600^{\circ} \mathrm{C}$ has a highly efficient sorption performance(Zhang et al., 2013; Zhang and Gao, 2013). Therefore, this paper sets the final pyrolysis temperature as $600^{\circ} \mathrm{C}$, and the detailed pyrolysis parameters are as follows: To ensure an inert atmosphere, the furnace was purged with 
nitrogen for 5 minutes, and then heated at $5{ }^{\circ} \mathrm{C} / \mathrm{min}$ to $110^{\circ} \mathrm{C}$ and held for 30 minutes, and then to $600{ }^{\circ} \mathrm{C}$ at $5{ }^{\circ} \mathrm{C} / \mathrm{min}$ and held for 60 min under constant nitrogen flow of approximately $115 \mathrm{~mL} / \mathrm{min}$. Samples were cooled in a nitrogen atmosphere to prevent oxidation.

Raw samples were named as: RL (Raw Oak Leaves) and RC (Raw cellulose). Pyrolyzed biochars were named as PL (Pyrolyzed leaves); PLK (Pyrolyzed Leaves + Kaolinite); PLM (Pyrolyzed Leaves + Montmorillonite); PLS (Pyrolyzed Leaves + Sand); PC (Pyrolyzed Cellulose); PCK (Pyrolyzed Cellulose + Kaolinite); PCM (Pyrolyzed Cellulose + Montmorillonite); PCS (Pyrolyzed Cellulose + Sand) followed by the mass fraction of clay minerals, e.g. LK5, LK10, CM5, CM10, etc.

\subsection{Biochar characterization}

A Mettler-Toledo TGA-DSC-1 thermogravimetric analyzer-differential scanning calorimeter was used to determine proximate analysis of biomass and biochar. Briefly, samples were loaded into $70 \mu \mathrm{L}$ alumina crucibles. Samples were heated from room temperature to $110^{\circ} \mathrm{C}$ under $20 \mathrm{~mL} / \mathrm{min} \mathrm{N}_{2}$ gas and held for 30 minutes to remove moisture. Samples were then heated at $10^{\circ} \mathrm{C} / \mathrm{min}$ to $900^{\circ} \mathrm{C}$ and held for 60 minutes (loss attributed to volatile matter), and then the gas was switched to dry air and sample heated to $950^{\circ} \mathrm{C}$, held for 60 minutes (loss attributed to fixed carbon, residual loosely termed "ash.") The ultimate analysis on the raw biomass and biochar was conducted using a CHNS Elemental Analyzer (Vario Macro Cube, Germany).

Nitrogen adsorption isotherms, performed on a Quantachrome Autosorb-iQ, were used to measure the surface areas and porosities of the biochars. Samples were degassed 
at $180^{\circ} \mathrm{C}$ for a minimum of $12 \mathrm{~h}$ (with the exception of the raw biomass, which was degassed at $80^{\circ} \mathrm{C}$ to prevent pyrolysis), and then weighed on a Sartorius semimicrobalance to $\pm 0.1 \mathrm{mg}$. The Brunauer-Emmett-Teller (BET) adsorption method was employed over a partial pressure range of $0.05-0.3$ in ultra high purity nitrogen at liquid nitrogen temperature(Brunauer et al., 1938). Scanning electron microscope (SEM) imaging of the biochar samples was conducted on a Zeiss Supra 55VP field emission scanning electron microscope. FTIR spectra were recorded between 4000 and $400 \mathrm{~cm}^{-}$ ${ }^{1}$ on a Nicolet 380 Thermo Scientific spectrometer. Cation exchange capacity (CEC) was obtained using the ammonium acetate method in which $0.02 \mathrm{~g}$ of the biochar/clay was added to $5 \mathrm{~mL}$ of $0.5 \mathrm{M}$ ammonium acetate solution. The mixture was agitated for $6 \mathrm{~h}$, filtered, and the filtrate kept for inductively coupled plasma-mass spectrum (ICPMS) analysis of $\mathrm{Na}^{+}, \mathrm{K}^{+}, \mathrm{Ca}^{2+}$, and $\mathrm{Mg}^{2+}$. The exchangeable cations were determined via:

Exch. Ca $=\frac{C_{0} \times 5}{10 \times 20.04 \times m_{0}}-\frac{C_{1} \times 5}{10 \times 20.04 \times m_{1}}$ Exch. $\mathrm{Mg}=\frac{C_{0} \times 5}{10 \times 12.15 \times m_{0}}-\frac{C_{1} \times 5}{10 \times 12.15 \times m_{1}}$ Exch. $\mathrm{K}=\frac{C_{0} \times 5}{10 \times 39.1 \times m_{0}}-\frac{C_{1} \times 5}{10 \times 39.1 \times \mathrm{m}_{1}}$ Exch. Na $=\frac{C_{0} \times 5}{10 \times 23.0 \times m_{0}}-\frac{C_{1} \times 5}{10 \times 23.0 \times m_{1}}$ Where $\mathrm{C}_{0}=$ concentration of $\mathrm{Ca}, \mathrm{Mg}, \mathrm{K}$, and $\mathrm{Na}(\mathrm{mg} / \mathrm{L})$ from the extract solution; $\mathrm{C}_{1}=$ concentration in blank solution; $\mathrm{m}_{0}=$ weigh of biochar/clay $(\mathrm{g})$ in ammonium acetate solution $\mathrm{m}_{1}=$ weigh of biochar/clay $(\mathrm{g})$ in ultrapure water; and $5=$ volume of $\mathrm{NH}_{4} \mathrm{OAc}$ used in $\mathrm{mL} .40 .078,24.305,39.098,22.99$ are the atomic weights of $\mathrm{Ca}, \mathrm{Mg}, \mathrm{K}$, and $\mathrm{Na}$, respectively, in $\mathrm{g} / \mathrm{mol}$. The cation exchange capacity is the summation of $\mathrm{Ca}^{2+}$, 
$\mathrm{Mg}^{2+}, \mathrm{Na}^{+}$, and $\mathrm{K}^{+}$exchangeable cations.

\subsection{Application of biochar to water treatment}

To determine the effect of different clay minerals on resulting biochars' adsorption potential, we used the pure biomass-char and $5 w t \%$ mineral loaded biochars in standard methylene blue (MB) adsorption kinetics and isotherm experiments(Visa et al., 2010). Batch adsorption isotherm experiments were run in $5 \mathrm{~mL}$ glass vials with a 1:500 ratio (0.008 g biochar in $4 \mathrm{~mL}$ solution) using MB solutions having initial concentrations from 20 to $200 \mathrm{mg} / \mathrm{L}$ at room temperature.

Kinetic adsorption experiments were carried out using a $50 \mathrm{~mL}$ flask at room temperature with a 1:500 (0.08 g biochar in $40 \mathrm{~mL}$ solution). $100 \mathrm{mg} / \mathrm{L}$ MB solution was used, and samples were collected at time intervals of 5, 10, 20, $30 \mathrm{~min}$, and 1,2, 4, $6,8,24,48 \mathrm{~h}$. The samples were shaken on a shaker table at $100 \mathrm{rpm}$, and samples were withdraw using a pipette, and immediately filtered through $0.45 \mu \mathrm{m}$ pore size hydrophilic PVDF membrane filters.

Dye concentrations for both experiments were determined on a Shimadzu UV-vis 1800 spectrophotometer at $664 \mathrm{~nm}$.

\section{Results and discussion}

To test the hypothesis that clay minerals, known for their adsorptive properties, could enhance the adsorption capacity of biochars when co-pyrolyzed at relatively low loadings ( 5 and $10 \mathrm{wt} \%$ ), we fabricated a series of 14 biochars and characterized their resulting properties and adsorption capacities. 


\subsection{Characterization of biochars}

As noted in Table 1, the pure biomass chars (PL and PC) show higher volatile matter, fixed carbon and elemental $\mathrm{C}$ content versus the mineral-biochar composites. This is mainly because of the increased relative concentration of minerals. The carbon content of cellulose-based biochars was higher than that of the oak leaves-based biochars, indicating that raw biomass type more strongly influences the biochar's carbon level, rather than the specific mineral with which the biomass is mixed. Yao et al.(Yao et al., 2014) and Basta et al.(Basta et al., 2011, 2009) also suggested that the chemical constituents of raw material (the ratios of cellulose, lignin, and hemicellulose in a heterogeneous biomass) control the yield and quality of biochar. The nitrogen and sulphur contents of all the sample were comparable with each other and ranged from $0.5 \sim 0.8 \% / 0.03 \sim 0.06 \%$ and $0.2 \sim 0.4 \% / 0.51 \sim 0.67 \%$ for leave type/cellulose type. Comparing biochar of the same biomass type and mineral loading, the reported data showed that carbon content of MMT-biochar was the highest. MMT loading resulted in production of biochar with high carbon content; at the same time, stronger catalytic effect of MMT aided the loss of hydrogen as a result of cleavage of weak bonds in biochar. Since the surface and interlayers of MMT contains more Lewis sites and Brønsted sites than kaolinite, the performance of catalyzing hydrocarbon generation during biomass pyrolysis was significantly higher than that of other mineral(Luo et al., 2021; Yang et al., 2009). Hence, MMT might promote more organic matter devolatilization and subsequent resulting a biochar with higher carbon content and lower hydrogen content. The calculated atomic ratios of $\mathrm{O} / \mathrm{C} ; \mathrm{H} / \mathrm{C}$ and $(\mathrm{O}+\mathrm{N}) / \mathrm{C}$ for 
MMT-biochar was lower than the same biomass type with same weight clay loading. The reduction of $\mathrm{H} / \mathrm{C}$ in the biochar is an indication of effective carbonization of the biomass while a decrease in the ratio of $\mathrm{O} / \mathrm{C}$ is attributed to polarity reduction and the hydrophilicity nature of the biochar surface(Ahmad et al., 2012). The ratio of $\mathrm{H} / \mathrm{C}$ and $\mathrm{O} / \mathrm{C}$ were used as an indicator for carbonization and reduction in this ratio indicated that there was a loss of water and O-containing functional groups in the present of MMT catalyst, which converted the alkyl carbon to aromatic carbon(Uchimiya et al., 2011).

\subsubsection{Surface Area of Biochars}

The surface areas increase 1-2 orders of magnitude upon pyrolysis of the raw biomass. In addition, for leaf-based biochar, the surface area of the mineral-biochar with $5 w t \%$ loading was 2-4 times higher than PL, yet the surface area of cellulosemineral biochar was lower than PC. Proximate analysis suggested that mineral loaded chars have lower volatile matter contents because of the mineral-promoted devolatilization during the pyrolysis process (and increase in ash content and some fixed carbon from the minerals); MMT's catalytic performance was higher than that of kaolinite. In general, the pores of the solid biomass expand as the volatile substances escape, generating a biochar with a larger specific surface area than its raw biomass counterpart(Gao and Goldfarb, 2019). Interestingly, the surface areas of MMT-biochars were lower than those of the kaolinite-biochars, and while the surface area of the $5 \mathrm{wt} \%$ MMT and kaolinite biochars for the leaves were higher than the unamended biomass, the surface areas of all the mineral-biochar composites showed a decreasing trend with 
209 increasing mineral loading. This suggests that the porous voids formed during 210 devolatilization might be blocked by minerals or have collapsed (plausible given the 211 small ratio of volatile matter present), both of which would result in lower surface area 212 and pore volume(Dou and Goldfarb, 2017). 
Table 1. Proximate, ultimate, and surface area analyses results on composite biochars fabricated from minerals and either oak leaves or cellulose

\begin{tabular}{|c|c|c|c|c|c|c|c|c|c|c|c|c|c|c|}
\hline Samples & $\begin{array}{l}\mathrm{V}_{\mathrm{M}} \\
(\%)\end{array}$ & $\begin{array}{l}\mathrm{FC} \\
(\%)\end{array}$ & $\begin{array}{l}\text { Ash } \\
(\%)\end{array}$ & $\begin{array}{l}\mathrm{C} \\
(\%)\end{array}$ & $\begin{array}{c}\mathrm{H} \\
(\%)\end{array}$ & $\begin{array}{c}\mathrm{O} \\
(\%)\end{array}$ & $\begin{array}{l}\mathrm{N} \\
(\%)\end{array}$ & $\begin{array}{c}\mathrm{S} \\
(\%)\end{array}$ & $\mathrm{H} / \mathrm{C}$ & $\mathrm{O} / \mathrm{C}$ & $(\mathrm{O}+\mathrm{N}) / \mathrm{C}$ & $\begin{array}{c}\mathrm{S}_{\mathrm{BET}} \\
\left(\mathrm{m}^{2} / \mathrm{g}\right)\end{array}$ & $\begin{array}{c}\mathrm{V}_{\text {Total }} \\
\left(\mathrm{cm}^{3} / \mathrm{g}\right)\end{array}$ & $\begin{array}{l}\text { Pore } \\
\text { size } \\
(\mathrm{nm})\end{array}$ \\
\hline $\mathrm{RL}$ & 83.24 & 12.32 & 4.44 & 53.94 & 5.93 & 39.32 & 0.7 & 0.11 & 0.11 & 0.73 & 0.74 & 1.29 & 0.0025 & 6.903 \\
\hline PL & 28.44 & 58.32 & 13.24 & 70.25 & 2.38 & 27.37 & 0.8 & 0.44 & 0.03 & 0.39 & 0.40 & 21.61 & 0.032 & 2.427 \\
\hline PLK5 & 23.21 & 53.47 & 23.32 & 62.87 & 2.14 & 34.99 & 0.66 & 0 & 0.03 & 0.56 & 0.57 & 92.54 & 0.083 & 2.537 \\
\hline PLM5 & 21.13 & 59.05 & 19.82 & 64.6 & 2.22 & 33.18 & 0.73 & 0.38 & 0.03 & 0.51 & 0.52 & 75.16 & 0.062 & 2.592 \\
\hline PLS5 & 23.58 & 56.66 & 19.76 & 64.67 & 2.41 & 32.04 & 0.6 & 0.28 & 0.04 & 0.50 & 0.50 & 46.2 & 0.047 & 2.462 \\
\hline PLK10 & 16.63 & 48.25 & 35.12 & 57.44 & 3.77 & 37.85 & 0.57 & 0.37 & 0.07 & 0.66 & 0.67 & 91.91 & 0.078 & 3.4 \\
\hline PLM10 & 19.71 & 49.77 & 30.52 & 58.12 & 3.11 & 38.11 & 0.51 & 0.15 & 0.05 & 0.66 & 0.66 & 62.67 & 0.06 & 3.843 \\
\hline PLS10 & 23.92 & 35.05 & 41.03 & 54.17 & 4.68 & 39.96 & 0.76 & 0.43 & 0.09 & 0.74 & 0.75 & 36.43 & 0.035 & 3.849 \\
\hline $\mathrm{RC}$ & 95.41 & 4.36 & 0.23 & 44.45 & 6.22 & 49.34 & 0 & 0 & 0.14 & 1.11 & 1.11 & 1.22 & 0.0039 & 13.024 \\
\hline $\mathrm{PC}$ & 29.82 & 69.34 & 0.84 & 85.28 & 4 & 3.43 & 0 & 3.43 & 0.05 & 0.04 & 0.04 & 286.69 & 0.174 & 5.853 \\
\hline PCK5 & 19.51 & 62.67 & 17.82 & 73.5 & 2.18 & 24.33 & 0.03 & 0.51 & 0.03 & 0.33 & 0.33 & 284.73 & 0.181 & 3.607 \\
\hline PCM5 & 17.04 & 64.92 & 18.04 & 67.99 & 2.21 & 29.8 & 0.04 & 0.67 & 0.03 & 0.44 & 0.44 & 256.16 & 0.166 & 3.294 \\
\hline PCS5 & 28.23 & 44.56 & 27.21 & 67.45 & 5.83 & 26.12 & 0.04 & 0.56 & 0.09 & 0.39 & 0.39 & 255.12 & 0.157 & 4.068 \\
\hline PCK10 & 16.45 & 45.13 & 38.42 & 59.83 & 3.65 & 35.86 & 0.05 & 0.61 & 0.06 & 0.60 & 0.60 & 250.2 & 0.164 & 2.62 \\
\hline PCM10 & 15.12 & 55.36 & 29.52 & 60.12 & 3.14 & 36.04 & 0.05 & 0.65 & 0.05 & 0.60 & 0.60 & 229.78 & 0.157 & 2.733 \\
\hline PCS10 & 16.04 & 31.02 & 52.94 & 58.66 & 4.24 & 36.48 & 0.06 & 0.56 & 0.07 & 0.62 & 0.62 & 223.84 & 0.139 & 2.481 \\
\hline
\end{tabular}




\subsubsection{FTIR analysis}

The FTIR spectra of the prepared biochars is shown in Figure 1. The surfaces of the two types of clay-based biochars are rich in $-\mathrm{OH},-\mathrm{C}-\mathrm{O},-\mathrm{COO}$ and $-\mathrm{C}-\mathrm{H}$ groups. Compared with PC/PL, new bands in MMT-biochar and kaolinite-biochar appeared, including for Si-O $\left(470 \mathrm{~cm}^{-1}\right)$, -C-H $\left(810 \mathrm{~cm}^{-1}\right),-\mathrm{C}-\mathrm{O} /-\mathrm{C}=\mathrm{O}\left(1037 / 1073 \mathrm{~cm}^{-1}\right),-\mathrm{COO} /-$ $\mathrm{C}=\mathrm{C}\left(1571 / 1580 \mathrm{~cm}^{-1}\right)$ and $-\mathrm{OH}\left(3430 / 3459 \mathrm{~cm}^{-1}\right)$. Given the large increase, especially in oxygen-containing groups (beyond what might be expected by adding 5 or $10 \mathrm{wt} \%$ of minerals that contain relatively low oxygen contents), we suspect that the minerals both "add" to the surface character (e.g. through addition of Si-O groups) and interact with the biochar's carbons to enhance the oxygenated groups on the surface of the at $1039 / 1073 \mathrm{~cm}^{-1}$, along with the small peaks at $3430 / 3459 \mathrm{~cm}^{-1}$ indicated the carboxyl group, hydroxyl group and lactone(Sun et al., 2015) increase with MMT and kaolinite addition (and actually decrease with sand). Therefore, the loading of MMT and kaolinite can strengthen the aromatic structure of pyrolyzed-char, and also increases

233 the oxygen-containing functional groups such as dehydrocarboxyl, carbonyl and hydroxyl groups. 

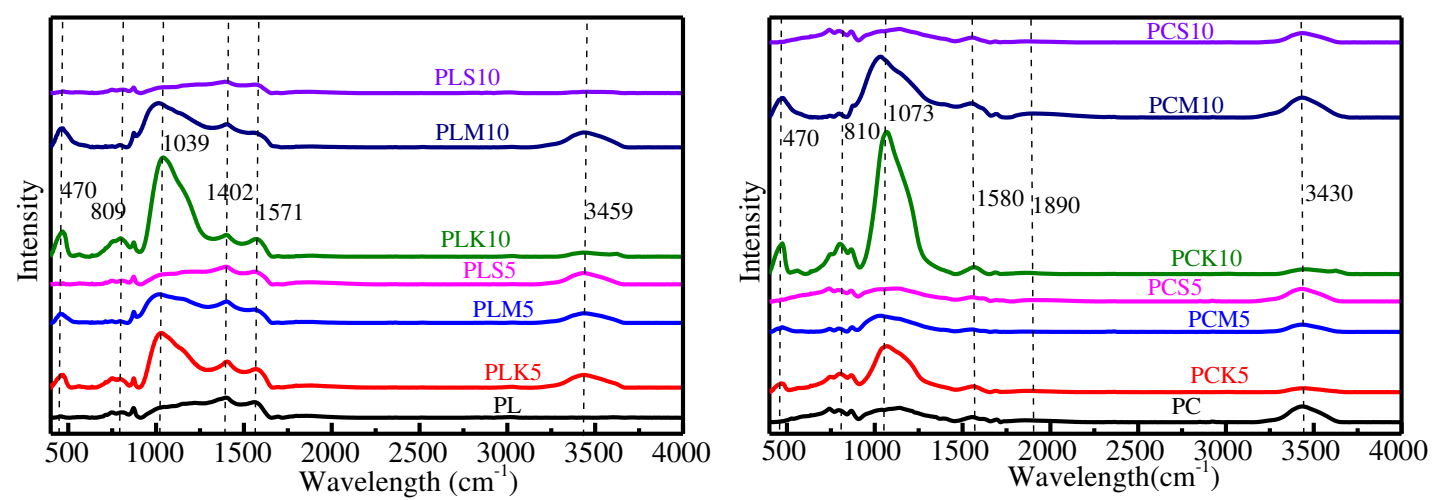

Figure 1. FTIR spectra of prepared biochar

\subsubsection{Cation exchange capacity}

The CEC is used to describe the potential of a biochar to adsorb positively charged substances. As shown in Figure 2, the CEC values of leaf-based biochars (ranging from 15 to $33 \mathrm{meq} / 100 \mathrm{~g}$ ) were higher than cellulose-based biochars (ranging from 1 to 35 meq/100 g). The CEC of oak leaf-biochar and cellulose-biochar was significantly lower than the CEC previously reported for biochar produced from sugar cane bagasse (122 meq/100g) pyrolyzed at $460{ }^{\circ} \mathrm{C}($ Carrier et al., 2012), although similar to the CEC reported for paper mill waste biochar (9-18 meq/100g)(van Zwieten et al., 2010). Suliman et al. reported that the CEC was a function of oxygenated functional groups and surface area of biochar(Suliman et al., 2016). However, the surface area of cellulose-based char was much higher than leaf-based char, indicating that surface area

248 of material was likely not the dominant factor controlling CEC. Khawmee et al.(Khawmee et al., 2013) and Basak et al.(Basak et al., 2020) showed that the CEC of a material was highly correlated with its metal content, oxygenated functional groups, Lewis acid and base sites, which may be consistent with the results of this work. We can see that the mineral loading had different effects on the various biochars. 
The measured CEC value of MMT/sand-leaf biochar or kaolinite/sand-cellulose biochar was quite similar to the predicted value (if we assume that the contribution is a weighted fuction of the composites' constituents as: Predicted $\mathrm{CEC}=\mathrm{wt}_{\text {Mineral }} *($ Mineral CEC $)+\mathrm{wt}_{\text {Biomass }} *(\mathrm{PL} / \mathrm{PC} \mathrm{CEC})$, where $\mathrm{wt}$ is the mass fraction of the component in the blend), indicating the CEC values of these biochar-mineral composites were in an addtive nature way. However, the MMT loaded cellulose biochars $(19.34,35.41 \mathrm{meq} / 100 \mathrm{~g})$ have higher CEC than predicted ones $(5.10,9.05$ meq/100g). This may due to MMT addition increasing 1) the formation of oxygenated fucntional groups and 2) the Lewis acid sites of MMT itself.

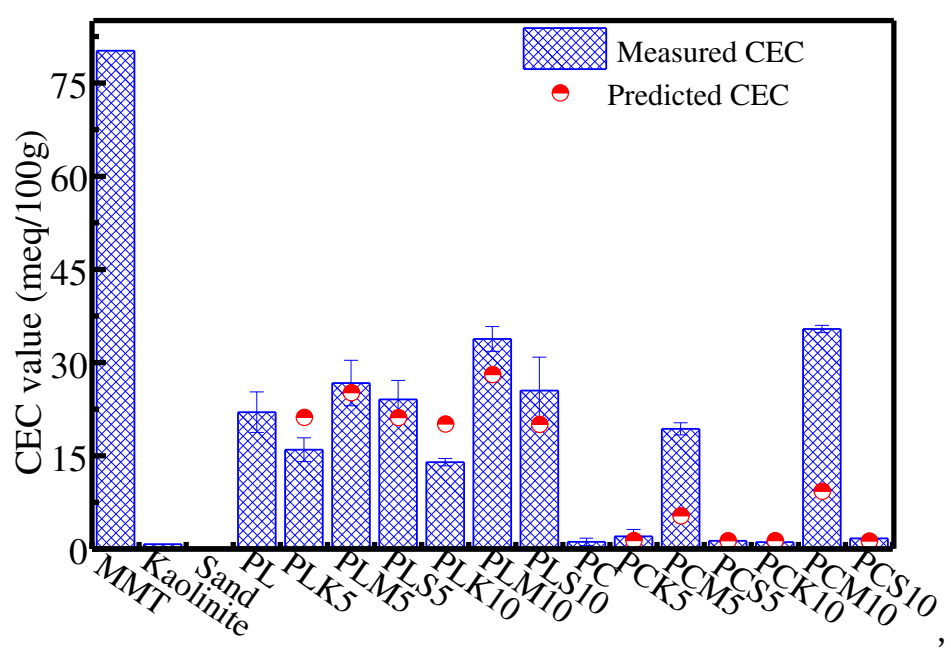

Figure 2. CEC values of prepared biochar

\subsubsection{SEM-EDX and XRD}

SEM images in Fig.3a show that the surface of composite samples (PCM5) is a layered structure, which is a common clay mineral structure(Yao et al., 2014; Zhou et al., 2009). EDX results (Fig.3b) show high contents of $\mathrm{Si}, \mathrm{Al}, \mathrm{Na}, \mathrm{Ca}$ and $\mathrm{Mg}$, further indicating that the composite surface is widely covered by clay minerals, despite their relatively low concentrations. Fig. $3 \mathrm{c}$ shows the distribution of $\mathrm{Ca}$ in the entire EDX test 

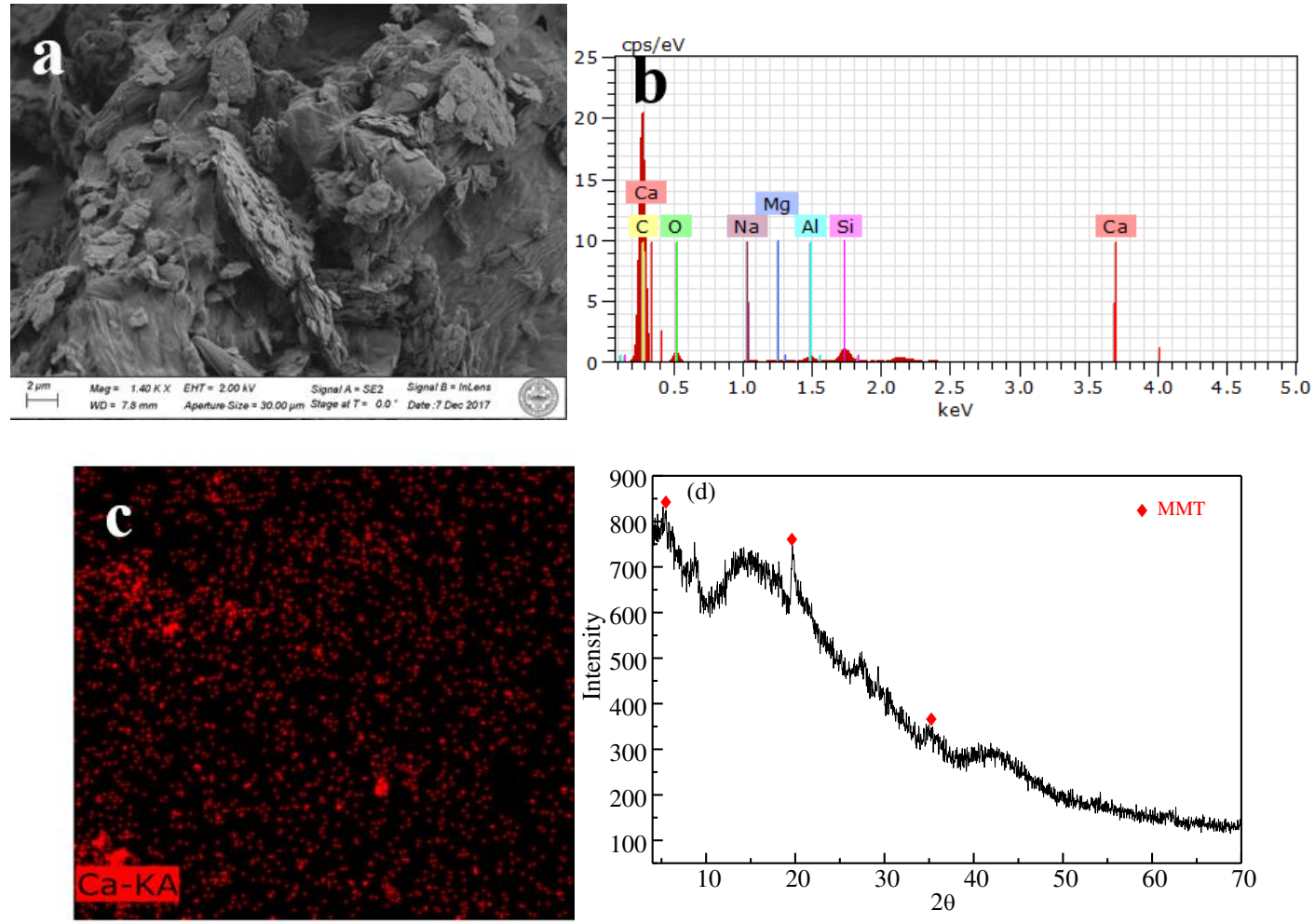

Figure 3. SEM images and XRD spectrum of prepared biochar (Cellulose with $5 w t \%$ MMT)

\subsection{Application of Biochars to Adsorption of Aqueous Contaminants}

\subsubsection{Equilibrium isotherm study}

The biochars with $5 w t \%$ mineral loading were used to determine the potential for these

composite biochars to remove aqueous organic contaminants. The resulting adsorption model parameters of MB onto biochar are presented in Table 2. Equilibrium adsorption studies indicate that the maximum adsorption capacities of the mineral-biochar composites ranging from 11 to $110 \mathrm{mg}_{\mathrm{MB}} / \mathrm{g}_{\text {biochar. }}$ Samples closely adhered to Langmuir isotherm as determined through correlation coefficients $\left(\mathrm{R}^{2}>0.99\right)$ for each model 
(Figure S1 and Table 2), indicating that adsorption of MB is monolayer and thus likely chemical in nature. As shown in Fig. 4(a), the cellulose-based biochars had a greater MB adsorption capacity than the oak leaf biochars. Surface modification with MMT and kaolinite did dramatically improve MB adsorption capacity for cellulose biochars, while it had no obvious effect on the adsorption capacity of leaf-based char, indicating that it may not suitable to apply the leaf-mineral composite for MB removal. For cellulose, the MMT modification improved the MB adsorption capacity from 23.915 $\mathrm{mgMB} / \mathrm{g}$ to $109.9653 \mathrm{mgMB} / \mathrm{g}$, while $36.444 \mathrm{mgMB} / \mathrm{g}$ for kaolinite modification. These results should be associated with the physico-chemical property of adsorbents. Generally, electrostatic attraction was the major adsorption interaction between engineered biochar and cationic dye MB(Wang et al., 2016). In order to verify the charge property of these biochars, zeta potential values in DI water were provided in Table 3. It could be found that all biochars showed negative surface charge, and PC possessing a highest zeta potential among them. Nonetheless, the uptake value of MB in PC was far lower than PCM5, which indicated that electrostatic attraction was not the key factor. Porous structure might facilitate better adsorption due to the favorable mass transportation and more active sites (Ge et al., 2018). Meanwhile, Li and Zhang investigated the influence of porous structure on the adsorption of MB, indicating 3.05 $\mathrm{nm}$ (which was the 5 times of MB three-dimensional structure depth) was the separation point (Li and Zhang, 2019). We could observe that cellulose biochar with a larger pore size (3.2-5.8 $\mathrm{nm}>3.05 \mathrm{~nm})$ exhibited much higher adsorption capacity than leaf-biochar with lower pore size $(\sim 2.5 \mathrm{~nm})$. Therefore, the coupling of other physico-chemical 
properties of biochar under larger pore size was the key factor for engineered biochar to adsorb MB.

The improvement in adsorption capacity (AC) as a function of clay mineral loading is likely not due to the higher $\mathrm{AC}$ contribution of clays alone, whose $\mathrm{AC}$ were measured to be 727.76 (MMT) and 18.67 (kaolinite) $\mathrm{mg}_{\mathrm{MB}} / \mathrm{g}_{\text {Adsorbent. The biomass: clay }}$ mineral ratio was initially 95:5, but the AC of PCM5 and PCK5 increased much higher than $5.26 \%$. If the clay mineral did not interact with biomass to increase the AC of composite, one might expect the resulting PCM5 AC to be $\sim 59 \mathrm{mg} / \mathrm{g}_{\text {Adsorbent }}$ [ if $\left.\left(\mathrm{AC}_{\text {predict }}=(0.95)\left(\mathrm{AC}_{\text {Cellulose biochar }}\right)+(0.05)\left(\mathrm{AC}_{\mathrm{MMT} / \mathrm{Kaolinite}}\right)\right)\right]$, yet the actual $\mathrm{AC}$ was almost twice this value. It might be predicted that PCK5 would have an AC of $\sim 23$ $\mathrm{mg} / \mathrm{g}_{\text {Adsorbent, }}$ yet it was $50 \%$ higher than this value. One explanation for the improved AC of composite is that the positive synergistic effect among the composites' physicochemical characterizations, such as surface area, CEC and elemental composition(Brindley and Thompson, 1970; Gürses et al., 2006; Klika et al., 2011).

\subsubsection{Adsorption dynamic study}

From Table 2 and Figure S4, we can see the adsorption of MB appeared to follow pseudo-second-order kinetics, which further underscores the conclusion that the adsorption of MB to biochar was chemical in nature, likely via electron pair transfer between $\mathrm{MB}$ and biochar. Similar results were obtained by $\mathrm{Yu}$ et al who reported electrons exchange between MB and biochar produced from microalgal was the ratelimiting step(Kai Ling Yu, Xin Jiat Lee, Hwai Chyuan Ong, Wei-Hsin Chen, Jo-Shu Chang, Chih- Sheng Lin, Pau Loke Show, 2020). In addition, we can see that the oak 
leaves-based biochar had a faster adsorption rate for MB compared with the cellulosebased biochar, and PCM5's adsorption rate was faster than other cellulose-based char. In order to understand major limitations in the adsorption process of MB onto mineral-biochar composites, the intra-particle diffusion model was applied to this data. Previous studies have suggested that if $\mathrm{q}_{\mathrm{t}} \mathrm{vs}$. $\mathrm{t}_{1 / 2}$ was a straight line and the plot passes through the origin, then intra-particle diffusion is the rate-limiting step in the adsorption process. Otherwise, the adsorption process is controlled by multiple steps(Hameed et al., 2008b; Jang et al., 2018; Kai Ling Yu, Xin Jiat Lee, Hwai Chyuan Ong, Wei-Hsin Chen, Jo-Shu Chang, Chih- Sheng Lin, Pau Loke Show, 2020). As shown in Fig 4(b), the $\mathrm{q}_{\mathrm{t}} \mathrm{vs} . \mathrm{t}_{1 / 2}$ was fitted by three straight line. The first stage (not shown) was completed within the first $5 \mathrm{~min}$, which is the bulk transport of MB molecules from aqueous solution to the composite's surface. The second and third parts are well represented by straight lines, suggesting that the intraparticle diffusion is the rate-limiting stage. In some cases (with the exception of PCM5 and PLM5), the third straight line was the final equilibrium stage where MB reaches a dynamic equilbrium between the aqueous phase and solid adsorbent. As shown in Fig. 4(b), the drawn straight lines did not pass through the origin and the intercepts might be result from the different mass transfer rate between initial and final of adsorption, indicating other possible mechanisms such as diffusion boundary layer or ion-exchange along with intraparticle diffusion were involved during the adsorption process of $\mathrm{MB}$ onto mineral-biochar composites(Kai Ling Yu, Xin Jiat Lee, Hwai Chyuan Ong, Wei-Hsin Chen, Jo-Shu Chang, Chih- Sheng Lin, Pau Loke Show, 2020; Lee et al., 2016). 
Hence the PCMS biochar act as a favorable one for MB dyes removal.

Figure 4. Equilibrium and kinetics adsorption results of MB onto prepared biochar

\subsubsection{Comparison with other reported adsorbents}

A comparative study was made based on uptake capacity between several bio-char composite adsorbents and the PCM5 for the removal of MB dye. In comparison to other adsorbents, the removal efficiency of the dye was found to be high in PCM5 (Table 4).
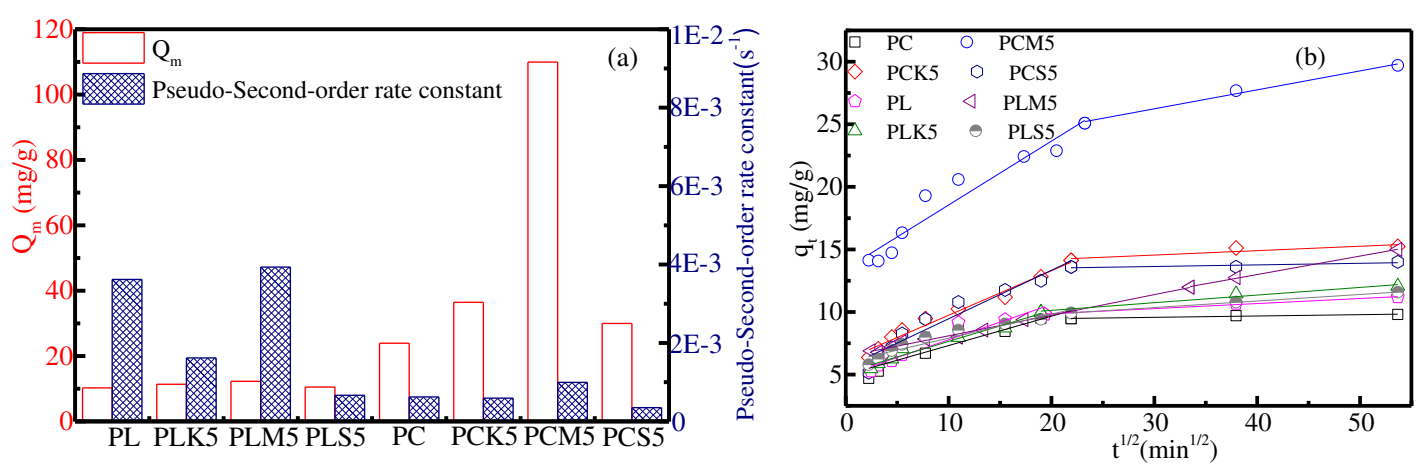
Table 2. Adsorption model parameters of MB onto biochar

\begin{tabular}{|c|c|c|c|c|c|c|c|c|c|}
\hline \multicolumn{2}{|c|}{ Isotherm/Kinetics Model } & PL & PLK5 & PLM5 & PLS5 & $\mathrm{PC}$ & PCK5 & PCM5 & PCS5 \\
\hline \multicolumn{2}{|r|}{$\mathrm{K}_{\mathrm{L}}(\mathrm{L} / \mathrm{mg})$} & 0.603 & 0.267 & 0.170 & 0.170 & 0.772 & 0.374 & 0.3276 & 0.0512 \\
\hline \multicolumn{2}{|r|}{$\mathrm{Q}_{\mathrm{m}}(\mathrm{mg} / \mathrm{g})$} & 10.256 & 11.351 & 12.270 & 10.504 & 23.915 & 36.444 & 109.9653 & 29.9760 \\
\hline \multirow[t]{3}{*}{ Langmuir } & $\mathrm{R}^{2}$ & 0.993 & 0.993 & 0.983 & 0.988 & 0.994 & 1.000 & 0.9997 & 0.9966 \\
\hline & $\mathrm{K}_{\mathrm{f}}\left(\mathrm{mg} / \mathrm{g}(\mathrm{L} / \mathrm{mg})^{1 / \mathrm{n}}\right)$ & 5.292 & 1.607 & 4.262 & 1.562 & 16.423 & 28.104 & 3.9700 & 9.0761 \\
\hline & $\mathrm{n}$ & 5.790 & 4.852 & 4.110 & 5.160 & 11.302 & 19.694 & 0.5708 & 4.5641 \\
\hline \multirow[t]{2}{*}{ Freundlich } & $\mathrm{R}^{2}$ & 0.706 & 0.894 & 0.935 & 0.951 & 0.378 & 0.978 & 0.8533 & 0.8865 \\
\hline & $\mathrm{K}_{1}\left(\mathrm{~s}^{-1}\right)$ & 0.0014 & 0.0003 & 0.0009 & 0.0008 & 0.0026 & 0.0015 & 0.0028 & 0.0010 \\
\hline \multirow[t]{2}{*}{ Pseudo-first-order kinetic } & $\mathrm{R}^{2}$ & 0.528 & 0.799 & 0.918 & 0.775 & 0.746 & 0.880 & 0.9464 & 0.9000 \\
\hline & $\mathrm{K}_{2}\left(\mathrm{~s}^{-1}\right)$ & 0.004 & 0.0019 & 0.0047 & 0.0008 & 0.0007 & 0.0007 & 0.0012 & 0.0004 \\
\hline Pseudo-second-order kinetic & $\mathrm{R}^{2}$ & 0.999 & 0.997 & 0.995 & 0.987 & 0.994 & 0.997 & 0.9983 & 0.9971 \\
\hline Materials & \multicolumn{3}{|c|}{ Zeta potential $(\mathrm{mV})$} & \multicolumn{2}{|c|}{ Materials } & \multicolumn{3}{|c|}{ Zeta potential $(\mathrm{mV})$} & \\
\hline $\mathrm{PC}$ & \multicolumn{2}{|c|}{$-55.1 \pm 2.55$} & & \multicolumn{2}{|c|}{$\mathrm{PL}$} & \multicolumn{4}{|c|}{$-32.71 \pm 2.23$} \\
\hline PCM5 & \multicolumn{2}{|c|}{$-26.69 \pm 0.96$} & & \multicolumn{2}{|c|}{ PLM5 } & \multicolumn{4}{|c|}{$-22.96 \pm 3.40$} \\
\hline PCK5 & \multicolumn{2}{|c|}{$-32.96 \pm 2.29$} & & \multicolumn{2}{|c|}{ PLK5 } & \multicolumn{4}{|c|}{$-32.93 \pm 0.71$} \\
\hline PCS5 & \multicolumn{2}{|c|}{$-18.69 \pm 0.94$} & & \multicolumn{2}{|c|}{ PLS5 } & \multicolumn{4}{|c|}{$-9.01 \pm 0.92$} \\
\hline
\end{tabular}


Table 4 Comparison of adsorption capacity of PCM5 with other bio adsorbents

\begin{tabular}{cc}
\hline Bio-adsorbents & Adsorption Capacity(mg/g) \\
\hline Chitosan nanocomposite(Rahmi et al., 2019) & 20.49 \\
Coconut bunch waste (Hameed et al., 2008a) & 70.92 \\
Kaolin (Mouni et al., 2018) & 52.7 \\
Orange peel (Annadurai et al., 2002) & 13.9 \\
Tea waste (Uddin et al., 2009) & 85.1 \\
MMDM derived biochar (Hoslett et al., 2020) & 7.2 \\
Rice husk (Vadivelan and Vasanth Kumar, 2005) & 40.59 \\
PCM5 (This work) & 109.9 \\
\hline
\end{tabular}

\subsubsection{Comparison with other reported adsorbents}

The adsorption of MB onto biochar is a complex process, including multiple steps and mechanisms, mainly involving electrostatic interaction, hydrogen bonding, surface complexation, ion exchange and $\pi-\pi$ EDA interaction, etc(Alqadami et al., 2018; Liao et al., 2019; Yao et al., 2018). The nature of the adsorbent affects the relative contribution of these various interactions(Liao et al., 2012). Liao et al. indicated that surface area, oxygen and hydrogen content, aromatic $(\mathrm{H} / \mathrm{C})$ were related to van der waals' force, H-bonding and $\pi-\pi$ EDA interaction, respectively(Liao et al., 2012; Pan and Xing, 2008; Wang et al., 2011). To measure the relative magnitude of these interactions, a multiple linear regression model relating adsorption capacity $\left(\mathrm{q}_{\mathrm{m}}\right)$ and adsorbent physicochemical properties was developed in SPSS software. The conceptual model is expressed as follows:

$$
q_{m}=a A_{\text {surf }}+b B_{\text {Pore volume }}+d D_{A s h}+e E_{H / C}+f F_{O / C}+g G_{C E C}+h H_{O+H}+
$$
$i$ Eq.(1)

Where a,b,c,d,e,f,g,h and i represent fitting constants. Both mineral-biochar composite properties of surface area $\left(\mathrm{A}_{\text {surf }}\right)$, pore volume $\left(\mathrm{B}_{\text {Pore volume }}\right)$, pore size $\left(\mathrm{C}_{\text {Pore }}\right.$ size), ash content $\left(\mathrm{D}_{\text {ash }}\right)$, aromatic ratio of hydrogen to carbon $\left(\mathrm{E}_{\mathrm{H} / \mathrm{C}}\right)$, polarity ratio of 
oxygen to carbon $\left(\mathrm{F}_{\mathrm{O} / \mathrm{C}}\right)$, cation exchange capacity $\left(\mathrm{G}_{\mathrm{CEC}}\right)$, oxygen and hydrogen content $\left(\mathrm{H}_{\mathrm{O}+\mathrm{H}}\right)$ are used to give an overall measurement of the interaction. (Previous studies have shown that surface area and pore volume ${ }^{37}$, ash (Liu et al., 2020), elemental content(Chen et al., 2017; Liao et al., 2012; Zhao and Zhou, 2019) and CEC(Chen et al., 2017) are all related to adsorption performance). 

oxygen and hydrogen content were the controlling properties of mineral-biochar 402 composites to adsorb MB. To increase the adsorption capacity of MB, it may be necessary to apply pore reaming and surface modification coupled methods (such as physical activation-steaming exploration(Miao et al., 2019), chemical activation-KOH activation( $\mathrm{Qu}$ et al., 2021)) to produce a composite with higher pore volume and increase the oxygen and hydrogen content. Further research will explore the relationship between adsorbent properties and coexistence of multiple pollutants with different nature, then developing and designing the upgraded biochar to removal pollutants with maximum capacity.

Table 3. Coefficients of the multiple linear regression equation

\begin{tabular}{ccccccc}
\hline & \multicolumn{2}{c}{$\begin{array}{c}\text { Unstandardized } \\
\text { coefficients }\end{array}$} & \multicolumn{3}{c}{$\begin{array}{c}\text { Standardized } \\
\text { coefficients }\end{array}$} & \multicolumn{3}{c}{$\begin{array}{c}\text { Collinearity } \\
\text { statistics }\end{array}$} \\
\cline { 2 - 7 } Explicative variable & $\mathrm{B}$ & Beta & $t$ & Sig. & Tolerance & VIF $^{\mathrm{a}}$ \\
\hline $\mathrm{i}$ & -321.923 & & -2.518 & 0.241 & & \\
Pore volume & 1029.738 & 1.921 & 4.512 & 0.139 & 0.203 & 4.934 \\
$\mathrm{Ash}$ & -14.609 & -3.426 & -1.41 & 0.393 & 0.006 & 160.69 \\
$\mathrm{H} / \mathrm{C}$ & 1268.744 & 0.707 & 1.142 & 0.458 & 0.096 & 10.411 \\
$\mathrm{O} / \mathrm{C}$ & -159.944 & -0.768 & -0.388 & 0.765 & 0.009 & 106.697 \\
$\mathrm{CEC}$ & 0.453 & 0.147 & 0.153 & 0.903 & 0.04 & 24.895 \\
$\mathrm{O}+\mathrm{H}$ & 16.899 & 4.755 & 1.789 & 0.325 & 0.005 & 192.246 \\
\hline
\end{tabular}

${ }^{a}$ Variance of inflation factor, $\mathrm{VIF}=1 /$ Tolerance. (VIF $>10$, indicating that there is a significant multiple linear relationship between variables).

\section{Conclusions}

A composite mineral-biochar was assembled through the pyrolysis of biomassmineral blends. Compared with pure biomass char, the sand-char has almost same properties, while the MMT-biochar composites show a strengthening in aromatic structure, and an increase in oxygen-containing surface functional groups and cation 
exchange capacity. Composite cellulose-based biochars had a greater adsorption capacity for methylene blue than oak leaves-based biochars, while their adsorption rates were lower than oak leaves chars. The MMT/kaolinite-biochar composite has a higher adsorption capacity for MB than biomass only or biomass-sand-char, and the adsorption capacity of $5 \mathrm{wt} \%$ MMT loading cellulose char is 5 times higher than pure cellulose char. The adsorption of methylene blue onto the mineral-biochar composites was a result of the synergistic effects of various interactions, as demonstrated via a multiparameter linear regression model. The pore volume effect and hydrogen bonding were the dominant factors controlling the adsorption process. Overall, we find that composite mineral-biochars may be a potential low-cost material with an upgraded adsorption capacity for adsorbing pollutants from wastewater.

\section{Acknowledgements}

L.Gao acknowledges the support of the Fundamental Research Funds for the Central Universities (Grant no. 2020QN37) and the support of the China Scholarship Council (CSC) under Grant CSC NO. 201606420017.

\section{Author contributions}

Lihui Gao: methodology, materials preparation, origin draft preparation; Jillian Goldfarb: review and editing.

Availability of data and materials: All data generated or analyzed during this study are included in this published article.

\section{Declarations}

Ethics approval and consent to participate: Not applicable 


\section{Consent for publication: Not applicable}

Conflict of interest: The authors declare no competing interests.

\section{References:}

Abou-El-Sherbini, K.S., Hassanien, M.M., 2010. Study of organically-modified montmorillonite clay for the removal of copper(II). J. Hazard. Mater. 184, 654-661. https://doi.org/10.1016/j.jhazmat.2010.08.088

Ahmad, M., Lee, S.S., Dou, X., Mohan, D., Sung, J.K., Yang, J.E., Ok, Y.S., 2012. Effects of pyrolysis temperature on soybean stover- and peanut shell-derived biochar properties and TCE adsorption in water. Bioresour. Technol. 118, 536-544. https://doi.org/10.1016/j.biortech.2012.05.042

Alqadami, A.A., Naushad, M., Alothman, Z.A., Ahamad, T., 2018. Adsorptive performance of MOF nanocomposite for methylene blue and malachite green dyes: Kinetics, isotherm and mechanism. J. Environ. Manage. 223, 29-36. https://doi.org/10.1016/j.jenvman.2018.05.090

Annadurai, G., Juang, R.S., Lee, D.J., 2002. Use of cellulose-based wastes for adsorption of dyes from aqueous solutions. J. Hazard. Mater. 92, 263-274. https://doi.org/10.1016/S03043894(02)00017-1

Basak, B.B., Saha, A., Sarkar, B., Kumar, B.P., Gajbhiye, N.A., Banerjee, A., 2020. Repurposing distillation waste biomass and low-value mineral resources through biochar-mineral-complex for sustainable production of high-value medicinal plants and soil quality improvement. Sci. Total Environ. 1, 1-10.

Basta, A.H., Fierro, V., El-Saied, H., Celzard, A., 2009. 2-Steps KOH activation of rice straw: An efficient method for preparing high-performance activated carbons. Bioresour. Technol. 100, 3941-3947. https://doi.org/10.1016/j.biortech.2009.02.028 
Basta, A.H., Fierro, V., Saied, H., Celzard, A., 2011. Effect of deashing rice straws on their derived activated carbons produced by phosphoric acid activation. Biomass and Bioenergy 35, 1954 1959. https://doi.org/10.1016/j.biombioe.2011.01.043

Brindley, G.W., Thompson, T.D., 1970. Methylene Blue Absorption by Montmorillonites. Determinations of Surface Areas and Exchange Capacities with Different Initial Cation Saturations (Clay-Organic Studies XIX). Isr. J. Chem. 8, 409-415. https://doi.org/10.1002/ijch.197000047

Brunauer, S., Emmett, P.H., Teller, E., 1938. Adsorption of Gases in Multimolecular Layers. J. Am. Chem. Soc. 60, 309-319. https://doi.org/citeulike-article-id:4074706\rdoi: 10.1021/ja01269a023

Carrier, M., Hardie, A.G., Uras, Ü., Görgens, J., Knoetze, J., 2012. Production of char from vacuum pyrolysis of South-African sugar cane bagasse and its characterization as activated carbon and biochar. J. Anal. Appl. Pyrolysis 96, 24-32. https://doi.org/10.1016/j.jaap.2012.02.016

Chcn, G., Pan, J., Han, B., Yan, H., 1999. Adsorption of methylene blue on montmorillonite. J. Dispers. Sci. Technol. 20, 1179-1187. https://doi.org/10.1080/01932699908943843

Chen, L., Chen, X.L., Zhou, C.H., Yang, H.M., Ji, S.F., Tong, D.S., Zhong, Z.K., Yu, W.H., Chu, M.Q., 2017. Environmental-friendly montmorillonite-biochar composites: Facile production and tunable adsorption-release of ammonium and phosphate. J. Clean. Prod. 156, 648-659. https://doi.org/10.1016/j.jclepro.2017.04.050

Dehkhoda, A.M., Ellis, N., Gyenge, E., 2016a. Effect of activated biochar porous structure on the capacitive deionization of $\mathrm{NaCl}$ and $\mathrm{ZnCl} 2$ solutions. Microporous Mesoporous Mater. 224, $217-$ 228. https://doi.org/10.1016/j.micromeso.2015.11.041

Dehkhoda, A.M., Gyenge, E., Ellis, N., 2016b. A novel method to tailor the porous structure of KOH- 
activated biochar and its application in capacitive deionization and energy storage. Biomass and Bioenergy 87, 107-121. https://doi.org/10.1016/j.biombioe.2016.02.023

Dou, G., Goldfarb, J., 2017. In situ upgrading of pyrolysis biofuels by bentonite clay with simultaneous production of heterogeneous adsorbents for water treatment. Fuel 195, 273-283. https://doi.org/10.1016/j.fuel.2017.01.052

Gao, L., Goldfarb, J.L., 2019. Solid waste to biofuels and heterogeneous sorbents via pyrolysis of wheat straw in the presence of fly ash as an in situ catalyst. J. Anal. Appl. Pyrolysis 137, 96-105. https://doi.org/10.1016/j.jaap.2018.11.014

Goldfarb, J.L., Buessing, L., Gunn, E., Lever, M., Billias, A., Casoliba, E.N., Schievano, A., Adani, F., Buessing, L., Botto, A., Casoliba, E.N., Rossoni, M., Goldfarb, J.L., 2017. Novel Integrated Biorefinery for Olive Mill Waste Management: Utilization of Secondary Waste for Water Treatment. ACS Sustain. Chem. Eng. 5, 876-884. https://doi.org/10.1021/acssuschemeng.6b02202

Gürses, A., Doğar, Ç., Yalçin, M., Açikyildiz, M., Bayrak, R., Karaca, S., 2006. The adsorption kinetics of the cationic dye, methylene blue, onto clay. J. Hazard. Mater. 131, 217-228. https://doi.org/10.1016/j.jhazmat.2005.09.036

Hameed, B.H., Mahmoud, D.K., Ahmad, A.L., 2008a. Equilibrium modeling and kinetic studies on the adsorption of basic dye by a low-cost adsorbent: Coconut (Cocos nucifera) bunch waste. J. Hazard. Mater. 158, 65-72. https://doi.org/10.1016/j.jhazmat.2008.01.034

Hameed, B.H., Tan, I.A.W., Ahmad, A.L., 2008b. Adsorption isotherm, kinetic modeling and mechanism of 2,4,6-trichlorophenol on coconut husk-based activated carbon. Chem. Eng. J. 144, 235-244. https://doi.org/10.1016/j.cej.2008.01.028 
Hoslett, J., Ghazal, H., Mohamad, N., Jouhara, H., 2020. Removal of methylene blue from aqueous solutions by biochar prepared from the pyrolysis of mixed municipal discarded material. Sci. Total Environ. 714, 136832. https://doi.org/10.1016/j.scitotenv.2020.136832

Istan, S., Ceylan, S., Topcu, Y., Hintz, C., Tefft, J., Chellappa, T., Guo, J., Goldfarb, J.L., 2016. Product quality optimization in an integrated biorefinery: Conversion of pistachio nutshell biomass to biofuels and activated biochars via pyrolysis. Energy Convers. Manag. 127, 576-588. https://doi.org/10.1016/j.enconman.2016.09.031

Jang, H.M., Yoo, S., Choi, Y.K., Park, S., Kan, E., 2018. Adsorption isotherm, kinetic modeling and mechanism of tetracycline on Pinus taeda-derived activated biochar. Bioresour. Technol. 259, 24-31. https://doi.org/10.1016/j.biortech.2018.03.013

Jiang, M. qin, Jin, X. ying, Lu, X.Q., Chen, Z. liang, 2010. Adsorption of Pb(II), Cd(II), Ni(II) and $\mathrm{Cu}(\mathrm{II})$ onto natural kaolinite clay. Desalination 252, 33-39. https://doi.org/10.1016/j.desal.2009.11.005

Kai Ling Yu, Xin Jiat Lee, Hwai Chyuan Ong, Wei-Hsin Chen, Jo-Shu Chang, Chih- Sheng Lin, Pau Loke Show, T.C.L., 2020. Adsorptive removal of cationic methylene blue and anionic Congo red dyes using wet- torrefied microalgal biochar: equilibrium, kinetic and mechanism modeling. Environ. Pollut. 1-12. https://doi.org/10.1016/j.envpol.2020.115986

Khawmee, K., Suddhiprakarn, A., Kheoruenromne, I., Singh, B., 2013. Surface charge properties of kaolinite from Thai soils. Geoderma 192, 120-131. https://doi.org/10.1016/j.geoderma.2012.07.010

Kimetu, J.M., Hill, J.M., Husein, M., Bergerson, J., Layzell, D.B., 2014. Using activated biochar for greenhouse gas mitigation and industrial water treatment. Mitig. Adapt. Strateg. Glob. Chang. 21, 
Klika, Z., Pustková, P., Dudová, M., Čapková, P., Kliková, C., Grygar, T.M., 2011. The adsorption of methylene blue on montmorillonite from acid solutions. Clay Miner. 46, 461-471. https://doi.org/10.1180/claymin.2011.046.3.461

Lee, L.Y., Gan, S., Yin Tan, M.S., Lim, S.S., Lee, X.J., Lam, Y.F., 2016. Effective removal of Acid Blue 113 dye using overripe Cucumis sativus peel as an eco-friendly biosorbent from agricultural residue. J. Clean. Prod. 113, 194-203. https://doi.org/10.1016/j.jclepro.2015.11.016

Liao, P., Yuan, S., Zhang, W., Tong, M., Wang, K., 2012. Mechanistic aspects of nitrogen-heterocyclic compound adsorption on bamboo charcoal. J. Colloid Interface Sci. 382, 74-81. https://doi.org/10.1016/j.jcis.2012.05.052

Liao, Y., Li, L., Fan, S., 2019. Removal behavior and mechanism of methylene blue in aqueous solution by rice straw and rice straw- $\mathrm{Fe}_{3} \mathrm{O}_{4}$ composite. Acta Sci. Circumstantiae 39, 359-370. https://doi.org/10.13671/j.hjkxxb.2018.0318

Liu, B., Fu, M., Xiang, L., Feng, N., Zhao, H., Li, Y., Cai, Q., Li, H., Mo, C., Wong, M., 2020. Adsorption of microcystin contaminants by biochars derived from contrasting pyrolytic conditions: Characteristics, affecting factors, and mechanisms. Sci. Total Environ. 1-10.

Luo, W., Wan, J., Fan, Z., Hu, Q., Zhou, N., Xia, M., Song, M., Qi, Z., Zhou, Z., 2021. In-situ catalytic pyrolysis of waste tires over clays for high quality pyrolysis products. Int. J. Hydrogen Energy 46, 6937-6944. https://doi.org/10.1016/j.ijhydene.2020.11.170

Miao, Z., Gao, M., Wan, K., Pei, Z., He, Q., Ji, P., Bai, L., 2019. Modification of Zhaotong Lignite by Steam Explosion Treatment: Pore Structure and OXygen-Containing FUnctional Groups. Energy \& Fuels 33, 4033-4040. 
Mouni, L., Belkhiri, L., Bollinger, J.C., Bouzaza, A., Assadi, A., Tirri, A., Dahmoune, F., Madani, K., Remini, H., 2018. Removal of Methylene Blue from aqueous solutions by adsorption on Kaolin: Kinetic and equilibrium studies. Appl. Clay Sci. 153, 38-45. https://doi.org/10.1016/j.clay.2017.11.034

Murray, H.H., 1991. Overview - clay mineral applications. Appl. Clay Sci. 5, 379-395. https://doi.org/10.1016/0169-1317(91)90014-Z

Pan, B., Xing, B., 2008. Adsorption mechanisms of organic chemicals on carbon nanotubes. Environ. Sci. Technol. 42, 9005-9013. https://doi.org/10.1021/es801777n

Qu, J., Wang, Y., Tian, X., Jiang, Z., Deng, F., Tao, Y., Jiang, Q., Wang, L., Zhang, Y., 2021. KOHactivation porous biochar with high specific surface area for adsorptive removal of chromium(VI) and naphathalene from water:Affecting factors, mechanisms and reusability exploration. J. Hazard. Mater. 401, 1-10.

Rahmi, Ismaturrahmi, Mustafa, I., 2019. Methylene blue removal from water using $\mathrm{H}_{2} \mathrm{SO}_{4}$ crosslinked magnetic chitosan nanocomposite beads. Microchem. J. 144, 397-402. https://doi.org/10.1016/j.microc.2018.09.032

Segad, M., Jönsson, B., Åkesson, T., Cabane, B., 2010. Ca/Na montmorillonite: Structure, forces and swelling properties. Langmuir 26, 5782-5790. https://doi.org/10.1021/la9036293

Suliman, W., Harsh, J.B., Abu-lail, N.I., Fortuna, A., Dallmeyer, I., Garcia-perez, M., 2016. Influence of feedstock source and pyrolysis temperature on biochar bulk and surface properties. Biomass and Bioenergy 84, 37-48. https://doi.org/10.1016/j.biombioe.2015.11.010

Sun, P., Hui, C., Khan, R.A., Du, J., Zhang, Q., Zhao, Y.H., 2015. Efficient removal of crystal violet using $\mathrm{Fe}_{3} \mathrm{O}_{4}$-coated biochar: The role of the $\mathrm{Fe}_{3} \mathrm{O}_{4}$ nanoparticles and modeling study their 
adsorption behavior. Sci. Rep. 5, 1-12. https://doi.org/10.1038/srep12638

Tan, X., Liu, Shao-bo, Liu, Y., Gu, Y., Zeng, G., Hu, X., Wang, X., Liu, Shao-heng, Jiang, L., 2017. Biochar as potential sustainable precursors for activated carbon production: Multiple applications in environmental protection and energy storage. Bioresour. Technol. 227, 359-372. https://doi.org/10.1016/j.biortech.2016.12.083

Tan, X., Liu, Y., Zeng, G., Wang, X., Hu, X., Gu, Y., Yang, Z., 2015. Application of biochar for the removal of pollutants from aqueous solutions. Chemosphere $125,70-85$. https://doi.org/10.1016/j.chemosphere.2014.12.058

Tay, T., Ucar, S., Karagöz, S., 2009. Preparation and characterization of activated carbon from waste biomass. J. Hazard. Mater. 165, 481-485. https://doi.org/10.1016/j.jhazmat.2008.10.011

Uchimiya, M., Wartelle, L.H., Klasson, K.T., Fortier, C.A., Lima, I.M., 2011. Influence of pyrolysis temperature on biochar property and function as a heavy metal sorbent in soil. J. Agric. Food Chem. 59, 2501-2510. https://doi.org/10.1021/jf104206c

Uddin, M.T., Islam, M.A., Mahmud, S., Rukanuzzaman, M., 2009. Adsorptive removal of methylene blue by tea waste. J. Hazard. Mater. 164, 53-60. https://doi.org/10.1016/j.jhazmat.2008.07.131

Vadivelan, V., Vasanth Kumar, K., 2005. Equilibrium, kinetics, mechanism, and process design for the sorption of methylene blue onto rice husk. J. Colloid Interface Sci. 286, 90-100. https://doi.org/10.1016/j.jcis.2005.01.007

van Zwieten, L., Kimber, S., Morris, S., Chan, K.Y., Downie, A., Rust, J., Joseph, S., Cowie, A., 2010. Effects of biochar from slow pyrolysis of papermill waste on agronomic performance and soil fertility. Plant Soil 327, 235-246. https://doi.org/10.1007/s11104-009-0050-X

Vijayalakshmi, P., Bala, V.S.S., Thiruvengadaravi, K. V., Panneerselvam, P., Palanichamy, M., 
Sivanesan, S., 2010. Removal of Acid Violet 17 from Aqueous Solutions by Adsorption onto Activated Carbon Prepared from Pistachio Nut Shell. Sep. Sci. Technol. 46, 155-163. https://doi.org/10.1080/01496395.2010.484006

Visa, M., Bogatu, C., Duta, A., 2010. Simultaneous adsorption of dyes and heavy metals from multicomponent solutions using fly ash. Appl. Surf. Sci. 256, 5486-5491. https://doi.org/10.1016/j.apsusc.2009.12.145

Wang, X., Shu, L., Wang, Y., Xu, B., Bai, Y., Tao, S., Xing, B., 2011. Sorption of peat humic acids to multi-walled carbon nanotubes. Environ. Sci. Technol. 45, 9276-9283. https://doi.org/10.1021/es202258q

Wang, X., Zhang, Y., Luo, W., Elzatahry, A.A., Cheng, X., Alghamdi, A., Abdullah, A.M., Deng, Y., Zhao, D., 2016. Synthesis of Ordered Mesoporous Silica with Tunable Morphologies and Pore Sizes via a Nonpolar Solvent-Assisted Stöber Method. Chem. Mater. 28, 2356-2362. https://doi.org/10.1021/acs.chemmater.6b00499

Wu, H., Lai, C., Zeng, G., Liang, J., Chen, J., Xu, J., Dai, J., Li, X., Liu, J., Chen, M., Lu, L., Hu, L., Wan, J., 2017. The interactions of composting and biochar and their implications for soil amendment and pollution remediation: a review. Crit. Rev. Biotechnol. 37, 754-764. https://doi.org/10.1080/07388551.2016.1232696

Yang, B., Cai, Z., Zhao, W., 2009. Catalysis of Different Clay Minerals to Kerabitumen in Hydrocarbon Genesis. Ed. Nat. Sci. 11, 68-71. https://doi.org/10.19406/j.cnki.cqkjxyxbzkb.2009.01.021

Yao, S., Zhang, M., Li, L., Liao, Y., Zhou, N., Fan, S., Tang, J., 2018. Preparation of tea waste-nano $\mathrm{Fe}_{3} \mathrm{O}_{4}$ composite and its removal mechanism of methylene blue from aqueous solution. Environ. 
Yao, Y., Gao, B., Fang, J., Zhang, M., Chen, H., Zhou, Y., Creamer, A.E., Sun, Y., Yang, L., 2014.

Zhang, M., Gao, B., 2013. Removal of arsenic , methylene blue, and phosphate by biochar/AlOOH nanocomposite. Chem. Eng. J. 226, 286-292. https://doi.org/10.1016/j.cej.2013.04.077 characterization of a novel magnetic biochar for arsenic removal. Bioresour. Technol. 130, 457462. https://doi.org/10.1016/j.biortech.2012.11.132

Zhao, Z., Zhou, W., 2019. Insight into interaction between biochar and soil minerals in changing 217. 
Figures
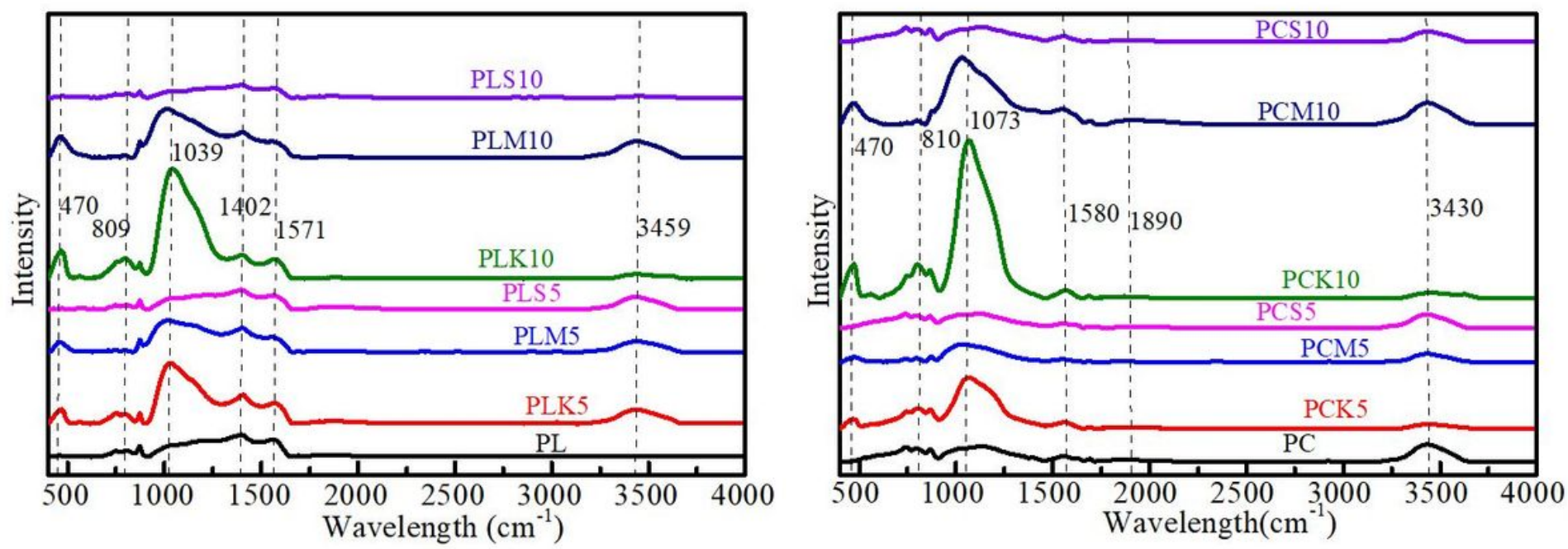

Figure 1

FTIR spectra of prepared biochar

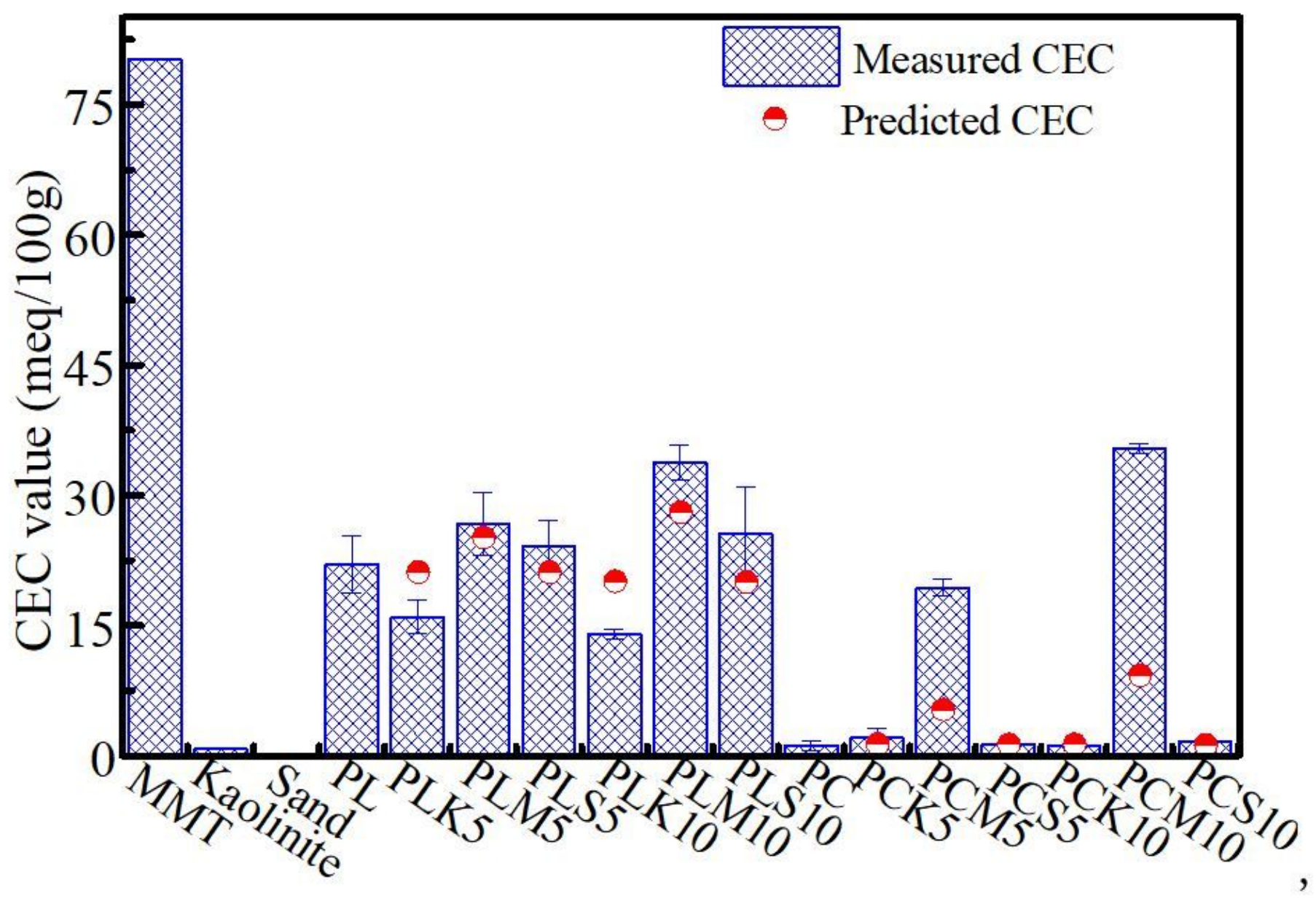

Figure 2 
CEC values of prepared biochar
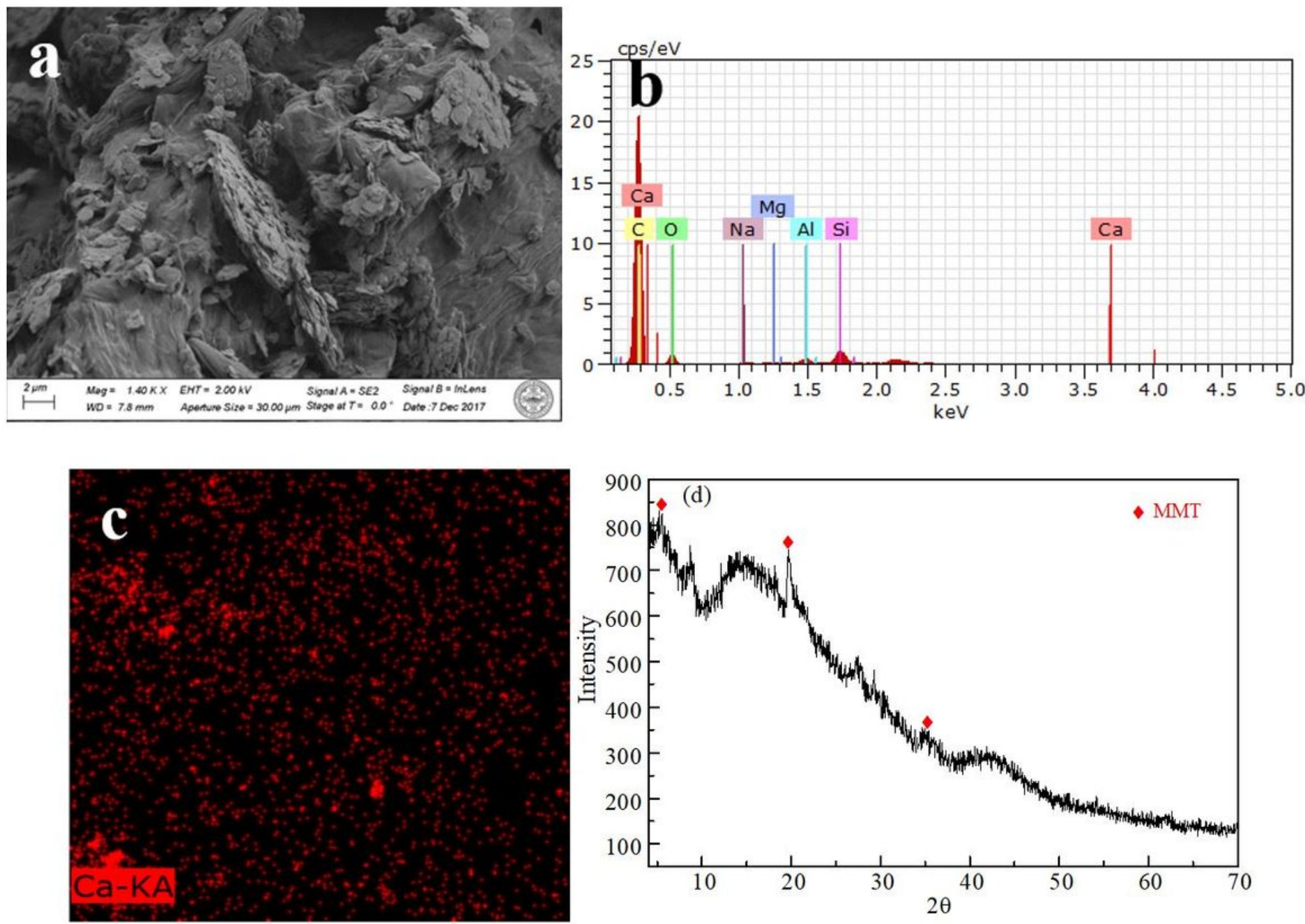

\section{Figure 3}

SEM images and XRD spectrum of prepared biochar (Cellulose with 5wt\% MMT)
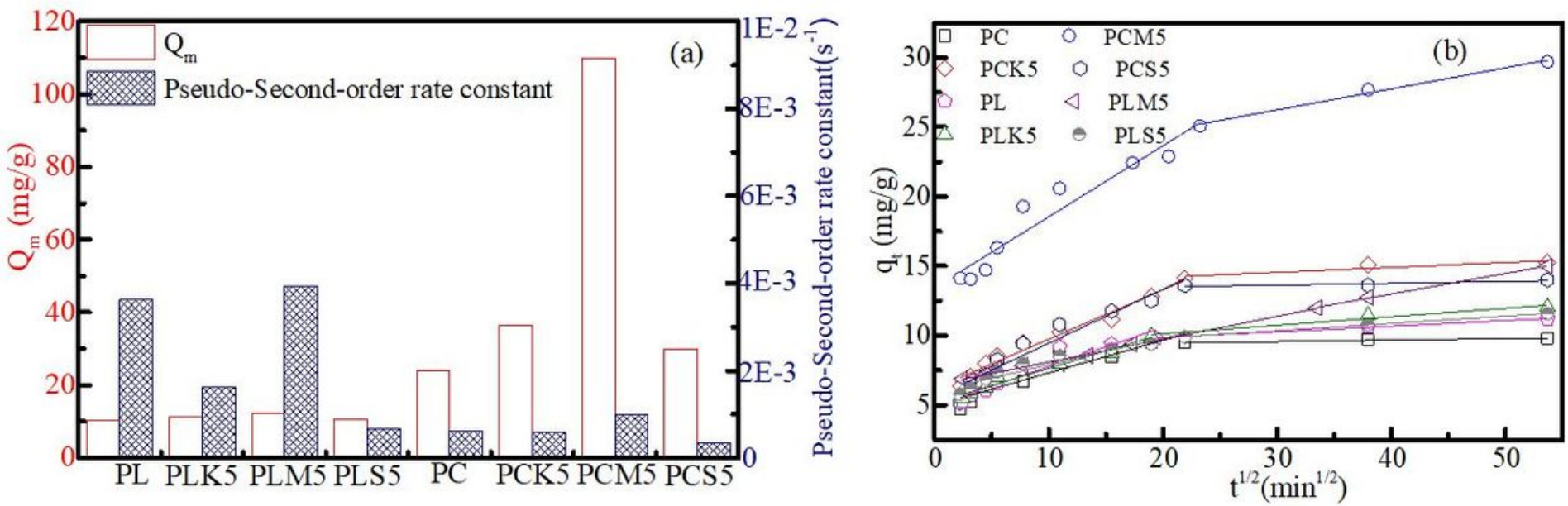

Figure 4 
Equilibrium and kinetics adsorption results of MB onto prepared biochar

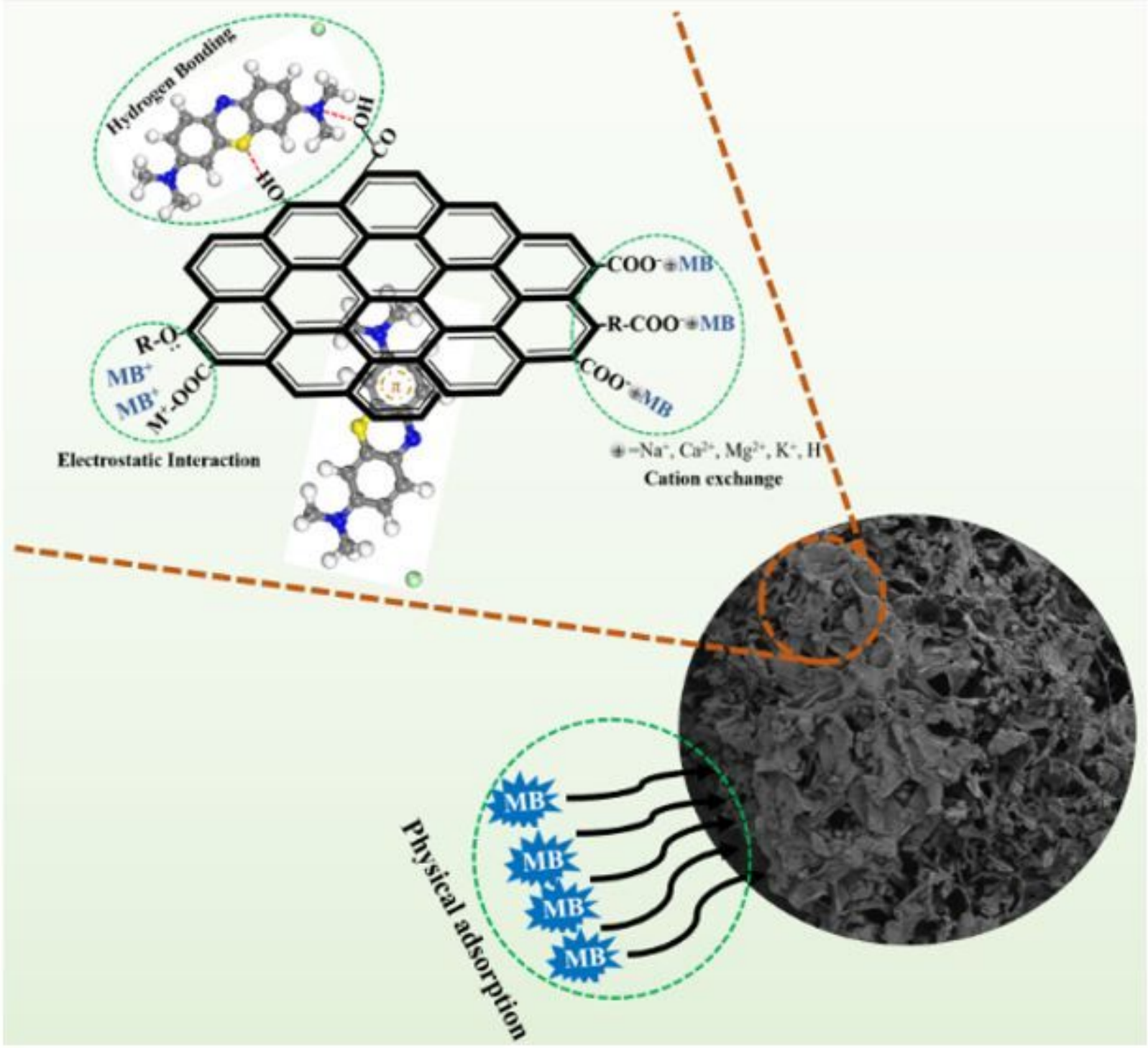

Figure 5

The mechanisms involved in MB adsorption onto mineral-biochar composites 